\title{
The Simple Economics of Optimal Auctions
}

\author{
Jeremy Bulow; John Roberts
}

The Journal of Political Economy, Vol. 97, No. 5. (Oct., 1989), pp. 1060-1090.

Stable URL:

http://links.jstor.org/sici?sici=0022-3808\%28198910\%2997\%3A5\%3C1060\%3ATSEOOA\%3E2.0.CO\%3B2-8

The Journal of Political Economy is currently published by The University of Chicago Press.

Your use of the JSTOR archive indicates your acceptance of JSTOR's Terms and Conditions of Use, available at

http://www.jstor.org/about/terms.html. JSTOR's Terms and Conditions of Use provides, in part, that unless you have obtained prior permission, you may not download an entire issue of a journal or multiple copies of articles, and you may use content in the JSTOR archive only for your personal, non-commercial use.

Please contact the publisher regarding any further use of this work. Publisher contact information may be obtained at http://www.jstor.org/journals/ucpress.html.

Each copy of any part of a JSTOR transmission must contain the same copyright notice that appears on the screen or printed page of such transmission.

The JSTOR Archive is a trusted digital repository providing for long-term preservation and access to leading academic journals and scholarly literature from around the world. The Archive is supported by libraries, scholarly societies, publishers, and foundations. It is an initiative of JSTOR, a not-for-profit organization with a mission to help the scholarly community take advantage of advances in technology. For more information regarding JSTOR, please contact support@jstor.org. 


\title{
The Simple Economics of Optimal Auctions
}

\section{Jeremy Bulow and John Roberts}

Stanford University

\begin{abstract}
We show that the seller's problem in devising an optimal auction is virtually identical to the monopolist's problem in third-degree price discrimination. More generally, many of the important results and elegant techniques developed in the field of mechanism design can be reinterpreted in the language of standard micro theory. We illustrate this by considering the problem of bilateral exchange with privately known values.
\end{abstract}

\section{Introduction}

An "optimal auction" is a bidding mechanism designed to maximize a seller's expected profit. The literature on optimal auctions has mushroomed in recent years (see, e.g., Harris and Raviv 1981a, 1981b; Myerson 1981; Riley and Samuelson 1981; Milgrom and Weber 1982; Matthews 1983; Maskin and Riley 1984a, 1984b) and has provided the basis for the more general study of efficient mechanism design. ${ }^{1}$

Unfortunately, this field has been a difficult one for most economists, seemingly bearing little relation to traditional price theory. This paper greatly simplifies the analysis of optimal auctions by showing

Much of the work reported here was done while Bulow was visiting the Graduate School of Business at the University of Chicago. We wish to thank Milton Harris, Paul Milgrom, Kevin M. Murphy, Roger Myerson, Hugo Sonnenschein, Sherwin Rosen, Bob Wilson, and an anonymous referee for valuable discussions and comments. The financial support of the Sloan Foundation and the National Science Foundation is gratefully acknowledged.

${ }^{1}$ Examples of research employing mechanism design techniques include studies of bilateral monopoly and bargaining (Myerson and Satterthwaite 1983), multilateral partial equilibrium exchange (Wilson 1985), regulation of a monopolist without knowing its costs (Baron and Myerson 1982), and dissolution of a partnership (Cramton, Gibbons, and Klemperer 1987). 
that it is essentially equivalent to the analysis of standard monopoly third-degree price discrimination. The auctions problem can therefore be solved by applying the usual logic of marginal revenue versus marginal cost. The same logic also clarifies the celebrated results on the revenue equivalence of various auctions and many of the results concerning bilateral monopoly.

Our primary purpose is not to obtain new results, though we do somewhat extend earlier work, but rather to connect existing results to familiar ideas. We hope that this reinterpretation of optimal auction theory will give readers a better understanding of a wide range of private information problems and, thus, perhaps lead to new insights.

\section{The Optimal Auction Problem}

The literature on optimal auctions begins with the work of Vickrey (1961). He considered the following situation. A seller values an item at zero. She has the option to sell it to one of $n$ risk-neutral bidders. Each bidder alone knows the value, $v$, that he places on the good. Because the seller and the other buyers are uncertain about this value, it appears to them to be a random variable. It is assumed to be common knowledge among all the buyers and the seller that everyone views the buyers' values as independent draws from a common distribution $F(v)$, with $F(\underline{v})=0$ and $F(\bar{v})=1$. That is, everyone (including i) agrees that the prior probability that $v_{i}$ is less than $v$ is given by $F(v)$, everyone knows that everyone knows this, everyone knows that everyone knows that everyone knows this, ad infinitum. The seller is considering two alternative ways to sell the item: a sealed-bid first-price auction, in which the high bidder wins and pays the amount he bid, and a sealed-bid second-price auction, in which the high bidder wins but pays only the amount bid by the second-highest bidder. The issue is, Which of these methods should the seller use to maximize her expected profit?

Either choice induces a game among the potential buyers, with each having to decide how much to bid as a function of his valuation for the good. Vickrey noted that when the second-price auction is used, each bidder has a dominant strategy of bidding his true valuation. This is because altering his bid from his value changes the outcome of the auction in only two cases: when underbidding causes him not to be the high bidder although his value is highest (so he gets a zero surplus instead of a positive one), and when bidding more than his value causes him to get the good but pay more than it is worth to him (because the next-highest bid exceeds his actual valuation).

Given that each bidder will announce his true value in the secondprice auction, it is clear that an individual with value $v$ will win with 
probability $F^{(n-1)}(v) \equiv[F(v)]^{(n-1)}$, which is just the probability that all others will have values (and bids) below $v$. It is also clear that his expected payment will be

$$
P(v) \equiv \int_{\underline{v}}^{v} w d F^{(n-1)}(w)=v F^{(n-1)}(v)-\int_{\underline{v}}^{v} F^{(n-1)}(w) d w
$$

and that his expected payment, contingent on winning, will be

$$
B(v) \equiv \frac{P(v)}{F^{(n-1)}(v)}=v-\frac{\int_{\underline{v}}^{v} F^{(n-1)}(w) d w}{F^{(n-1)}(v)},
$$

which is the expected value of the second-highest valuation, given that $v$ is the highest.

With a first-price auction, the strategic interaction among the bidders is not trivial; there is an incentive for each bidder to shade his bid below his value, trading off a reduced probability of winning against a lower payment if he wins. Vickrey showed that, in fact, it is equilibrium behavior for a bidder with value $v$ to bid the amount $B(v)$ defined above. (A largely graphical treatment of these results is provided in the Appendix.) Vickrey's celebrated revenue equivalence result follows immediately from $B(v)$ being the optimal bid. Given symmetric, risk-neutral bidders with independent valuations, the expected revenue from the first- and second-price auctions is the same because the bidder with the highest value always wins under either auction (note that $B(v)$ is increasing) and the winner's expected payment conditional on winning is the same amount, $B(v)$, under either auction.

Although there was a steady stream of work on auctions over the two decades following Vickrey's paper, the literature expanded dramatically during the 1980 s. A particularly seminal piece-both for the results obtained and for the methods introduced-is that of Myerson (1981). Myerson extended earlier work in two important ways. The first was to consider the case of asymmetric bidders, that is, bidders whose (privately known) valuations of the object are drawn from independent, but not necessarily identical, probability distributions. These distributions are assumed to be common knowledge, so that all bidders and the seller know the distribution from which each bidder's value is drawn. With resale excluded, this allows the seller to discriminate among bidders. The second extension was to consider all possible ways of selling the good rather than just a prespecified set of alternative auction forms as Vickrey had done. In this context, Myerson formulated and solved the "optimal auction design problem": among all possible ways of selling the good, which one should the seller use if she wants to maximize her expected net revenues? 
Myerson's solution gives an explicit formula for the optimal auction with asymmetric bidders. He also extended Vickrey's revenue equivalence result to show that any two mechanisms that always lead to the same allocation of the good (and meet one further trivial condition) would yield the same expected revenue. Finally, the methods he introduced have since been widely applied to other problems involving private information.

Note that the optimal auction design problem is extremely complex. There are a myriad of possible ways of allocating and charging for the good: a simple posted price; the various common forms of auctions, including first- and second-price sealed-bid auctions, and ascending and descending oral auctions (each of which could be modified by using reservation prices and fees charged for the privilege of bidding); less common auction forms such as the "all-pay" auction, in which the highest bidder wins but everyone pays the amount he bid $^{2}$ - the list seems limited only by the imagination.

The crucial breakthrough in this research effort was to identify a method of formulating the optimal auction problem that immensely simplified its solution. The key insight is to use the "revelation principle" (see Myerson [1981] for an exposition). This states that in searching for an optimal method of selling the good it is sufficient to consider only "direct revelation mechanisms." In these, bidders are asked to announce their valuations directly, and the seller commits herself to using rules for allocating the good and for charging the buyers that ensure both that the buyers will be willing to participate and that each will find it in his interest to announce his true valuation. Given this result, the problem of selecting an optimal way to sell the good reduces to a relatively simple constrained maximization problem: maximize the seller's expected revenues by the choice of functions giving the probability of allocating the good to each buyer and the payment to be made by each (both as functions of the announced values), subject to the "participation constraints" that each bidder receive nonnegative expected surplus and the "incentive constraints" that it be equilibrium behavior for bidders to reveal their true valuations.

While this is an immense simplification of the problem, its solution is still complex, and the literature on optimal auctions has remained difficult despite such excellent surveys as those of Milgrom (1985, 1987, 1989) and McAfee and McMillan (1987).

In the next section we present a simple and easily interpreted recipe for constructing the optimal auction. This approach connects directly to the standard monopoly problem of third-degree price dis-

\footnotetext{
${ }^{2}$ Lobbying and other rent-seeking activities and wars of attrition are examples of economic situations relevantly modeled as all-pay auctions.
} 
crimination. In Section IV, we show that this recipe actually works by arguing that Myerson's optimal auction problem is essentially mathematically identical to the price discrimination problem, and so their solutions are also in close correspondence. This connection between the two problems casts light on both. In Section $\mathrm{V}$ we then show how formulae derived in Section IV for the expected revenues of a monopolist or a seller in an auction yield a strong revenue equivalence result. Section VI is concerned with a technical problem corresponding to the marginal revenue curve's not being everywhere decreasing. Section VII contains a discussion of bilateral exchange when neither the buyer nor the seller knows the other's value. This section builds on the methods developed earlier and illustrates their wider applicability. Section VIII is a brief conclusion.

\section{A Recipe for Solving the Optimal Auction Problem in the "Regular Case"}

Assume that there are $n$ risk-neutral potential buyers for a good. Each buyer $i$ values the good at an amount $v_{i}$, known only to him, which is considered by everyone (including the buyer) to have been drawn from a distribution with cumulative density $F_{i}, F_{i}\left(\underline{v}_{i}\right)=0, F_{i}\left(\bar{v}_{i}\right)=1$. The draws for the different individuals are independent. The differing distributions from which buyer values are drawn are common knowledge among all buyers and the seller. The seller has a value known to be zero. (Generalization to the case in which the seller's value is a known, positive amount, $v_{0}$, is trivial.) What sales mechanism will maximize the seller's expected profits?

As a specific example, assume that A's value is drawn from a distribution with uniform density between zero and 10; B's value is drawn from a uniform distribution between 10 and 30 . If these are the only two bidders, a traditional English (open, ascending-bid) auction would lead to B's always winning and paying an expected price of five (where A will drop out on average). A minimum bid of 10 will cause B always to bid 10, raising expected revenue to 10 . A minimum bid of 15 will lead to no bids one-quarter of the time (when B's value is less than 15) and to a bid of 15 three-quarters of the time. Expected revenue becomes $3 / 4 \times 15=11.25$. Our question is, How does one construct a mechanism that extracts the maximum possible expected revenue? The answer is given below.

1. For each bidder, graph the inverse of his cumulative distribution function, with value $v$ on the $Y$ or "price axis" and the probability that the buyer's value exceeds a certain value, $1-F_{i}(v) \equiv q$, on the $X$ or "quantity axis." For each bidder, we then have something that looks like a demand curve, with the bidder's maximum possible value being 
the price at a quantity of zero and the bidder's minimum possible value being the price at a quantity of one.

2. From the demand curve for each bidder draw a marginal revenue curve, calculated the way we always calculate marginal revenue curves from demand curves: Multiply "quantity," $q=1-F_{i}(v)$, times "price," $v=F_{i}^{-1}(1-q)$, and take the derivative with respect to "quantity":

$$
\begin{aligned}
\frac{d q F_{i}^{-1}(1-q)}{d q} & =F_{i}^{-1}(1-q)+q \frac{d F_{i}^{-1}(1-q)}{d q} \\
& =F_{i}^{-1}(1-q)-\frac{q}{f_{i}\left(F_{i}^{-1}(1-q)\right)}
\end{aligned}
$$

Now express this as a function of $v:^{3}$

$$
\operatorname{MR}_{i}(v)=v-\frac{1-F_{i}(v)}{f_{i}(v)} .
$$

We define $\operatorname{MR}_{i}(v)=-\infty$ for all $v<\underline{v}_{i}$.

3. Conduct the following "second marginal revenue auction": $(a)$ Have each bidder announce his value. (We shall show below that bidders will not have an incentive to lie.) (b) Translate each bidder's value to a marginal revenue, which we shall assume for the moment is monotonically increasing in the buyer's value. Consider the seller to be a bidder with a value and marginal revenue of zero. (c) Award the good to the bidder with the highest marginal revenue. The price paid is the lowest value the bidder could have announced without losing the auction. If no bidder has a positive marginal revenue, then the seller "wins" the auction and there is no sale. If only one bidder's value translates to a positive marginal revenue (say that of bidder 1 ), then 1 gets the item at a price equal to his value $v_{i}^{*}$ at which $\operatorname{MR}_{1}\left(v_{l}^{*}\right)=0$, that is, at the lowest value he could have had and still had a positive marginal revenue. If more than one bidder announces a value that translates to a positive marginal revenue, the one with the highest marginal revenue (say bidder 1 ) gets the item at a price determined by taking the second-highest marginal revenue, say $M_{2}$, and charging the winner the value, $\mathrm{MR}_{1}^{-1}\left(M_{2}\right)$, that he would have had if his marginal revenue had been $M_{2}$.

Note that the bidder with the highest value will not always win the auction because he will not always have the highest marginal revenue. Note too that honest reporting of values is a dominant strategy for bidders. If a bidder wins the auction, the amount he pays is indepen-

\footnotetext{
${ }^{3}$ Those familiar with the optimal auctions literature will recognize this expression as Myerson's "virtual utility." Similar formulae often appear in incomplete information analyses and bear the interpretation given here.
} 


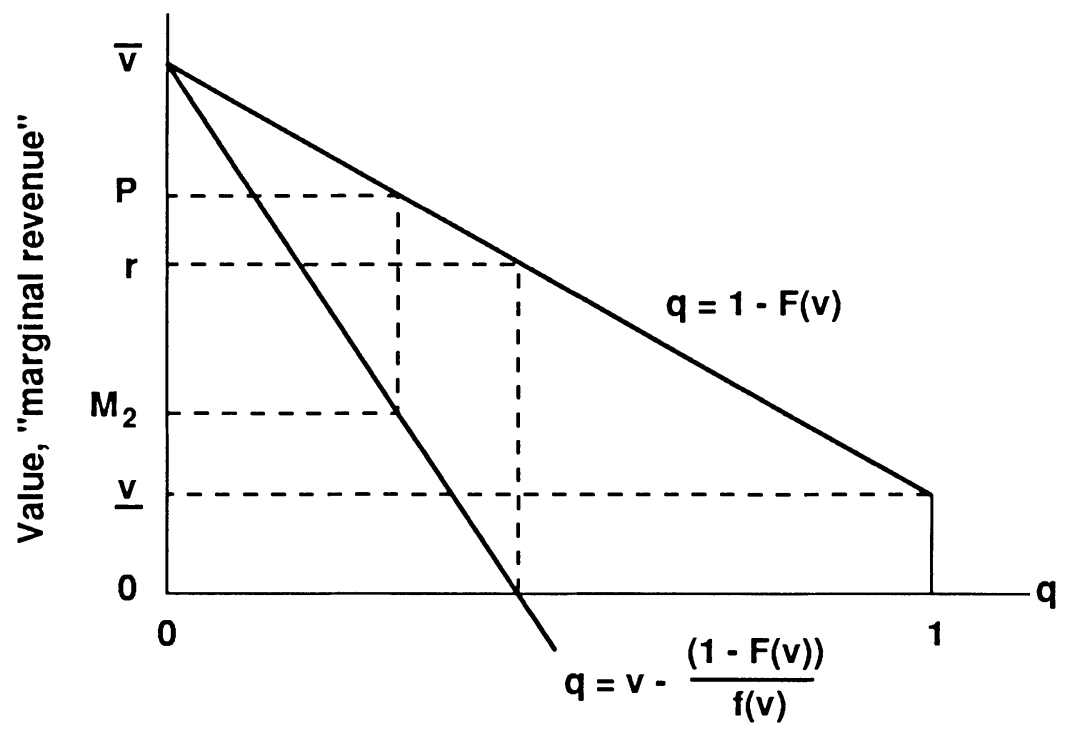

FIG. 1.-Construction of an optimal auction

dent of his report since it is always the lowest amount he could have bid and still have won. Any lie that changes the outcome of the auction will reduce the liar's utility, while any lie that does not affect the outcome also does not affect the amount paid by the liar and so does not change the liar's utility. Finally, note that the value at which a bidder's marginal revenue equals zero can be interpreted as a reservation price for this bidder since it is the lowest price he would ever be charged for the good, and there is no point to his bidding if his actual value is less than this level.

In figure 1 a buyer has a value distributed between $v$ and $\bar{v}$. The reservation price for him is set at $r$, which corresponds to his marginal revenue equaling zero. (In the case in which the seller's value is $v_{0}>0$, the reservation price would be set at the point at which the buyer's marginal revenue equals $v_{0}$.) If this bidder has the highest marginal revenue and the bidder with the next-highest marginal revenue has a marginal revenue of $M_{2}$, then this bidder will win the auction and pay a price of $P$, the lowest value he could have had and still have had the maximal marginal revenue. The other buyers pay nothing. For symmetric bidders this is clearly identical to a second-price auction; for asymmetric bidders, it is possible for one bidder to have the highest value and another the highest marginal revenue, just as in conventional price discrimination across markets.

In the numerical example considered above, buyer $\mathrm{A}$ with a value distributed uniformly between zero and 10 can be thought of as hav- 
ing the inverse demand curve $p_{\mathrm{A}}=10-10 q_{\mathrm{A}}$. His marginal revenue curve (in terms of quantity) is $p_{\mathrm{A}}=10-20 q_{\mathrm{A}}$. Similarly, B's demand curve is $p_{\mathrm{B}}=30-20 q_{\mathrm{B}}$, and his marginal revenue curve is $p_{\mathrm{B}}=30-$ $40 q_{\mathrm{B}}$. Substituting from the demand functions, we see that the corresponding $\mathrm{MR}_{i}$ functions are

$$
\begin{aligned}
& \operatorname{MR}_{\mathrm{A}}\left(v_{\mathrm{A}}\right)=10-20\left(\frac{10-v_{\mathrm{A}}}{10}\right)=2 v_{\mathrm{A}}-10, \\
& \operatorname{MR}_{\mathrm{B}}\left(v_{\mathrm{B}}\right)=30-40\left(\frac{30-v_{\mathrm{B}}}{20}\right)=2 v_{\mathrm{B}}-30 .
\end{aligned}
$$

Thus $\mathrm{MR}_{\mathrm{A}} \geq 0 \Leftrightarrow v_{\mathrm{A}} \geq 5, \mathrm{MR}_{\mathrm{B}} \geq 0 \Leftrightarrow v_{\mathrm{B}} \geq 15$, and $\mathrm{MR}_{\mathrm{A}} \geq \mathrm{MR} \mathrm{R}_{\mathrm{B}} \Leftrightarrow v_{\mathrm{A}}$ $\geq v_{\mathrm{B}}-10$. Consequently, if $v_{\mathrm{A}} \geq 5$ and $v_{\mathrm{A}}>v_{\mathrm{B}}-10$, A wins and pays the larger of his reservation price, five, and $v_{\mathrm{B}}-10$. If $v_{\mathrm{B}} \geq 15$ and $v_{\mathrm{B}}>v_{\mathrm{A}}+10, \mathrm{~B}$ is the winner at the price $\max \left(15, v_{\mathrm{A}}+10\right)$. If $v_{\mathrm{A}}$ $<5$ and $v_{\mathrm{B}}<15$, no sale is made. For example, if $\mathrm{A}$ announced his value as $v_{\mathrm{A}}=8$, then $\mathrm{MR}_{\mathrm{A}}=6$. If $\mathrm{B}$ announced his value as $v_{\mathrm{B}}=17$, then $\mathrm{MR}_{\mathrm{B}}=4$. So $\mathrm{A}$ would have the higher marginal revenue, even though $v_{\mathrm{A}}<v_{\mathrm{B}}$, and he would win the auction. He would pay seven since if $v_{A}$ were seven, then $M R_{A}$ would be four, the actual value of $\operatorname{MR}_{\mathrm{B}}\left(v_{\mathrm{B}}\right)$.

The major remaining detail is to discuss what happens when the marginal revenue curve of an individual is not monotonically decreasing in quantity or, equivalently, increasing in his value. This case will be discussed in Section VI.

Finally, it is easy to generalize to the optimal mechanism for an auction in which the seller has $k$ identical goods to sell, but each buyer still wants only one unit. Simply run a " $(k+1)$ st marginal revenue" auction, with each of the winners (the $k$ individuals with the highest marginal revenues) paying the price on his demand curve corresponding to the greater of the $(k+1)$ st marginal revenue and zero marginal revenue. Reservation prices remain as before if the seller's value of each item is zero. The generalization to a seller who can produce extra items at increasing marginal cost should also be clear. Sell $k$ units to the buyers with the $k$ highest marginal revenues, where the $k$ th-highest marginal revenue is greater than the marginal cost of the $k$ th unit and the $(k+1)$ st marginal revenue is less than the corresponding marginal cost. Each of the $k$ buyers pays the value on his demand curve associated with the greater of the $k$ th marginal cost and the $(k+1)$ st marginal revenue, in other words, the minimum value the buyer would have had to have to qualify to receive a unit.

This rule for the optimal auction reveals some interesting features. First, the allocation of the good may not be optimal ex post: the good may stay with the seller who values it at zero when a buyer places 
positive value on it, and, as noted, it may be allocated to one buyer when another values it more highly. Second, some simple comparative statics are possible. For example, raising the seller's valuation from zero to $v_{0}>0$ raises each individual's reservation price, from $\mathrm{MR}_{i}^{-1}(0)$ to $\mathrm{MR}_{i}^{-1}\left(v_{0}\right)$. Therefore, the probability of a sale falls. Suppose, however, that for a given set of buyers' values, a sale is still made. Then it will be made to the same bidder as before. Moreover, the price he pays will be affected only if the next highest marginal revenue is less than $v_{0}$, in which case the price rises to the buyer's new reservation price. As another example, consider any change in the distribution $F_{i}$ of buyer $i$ 's values that decreases $\mathrm{MR}_{i}$ as a function of $v_{i}$. This shift will raise bidder $i$ 's reservation price. Further, for any value of $v_{i}$, the shift will decrease $i$ 's probability of winning the good and increase the price he pays when he wins. In fact, it is easy to construct examples in which a buyer's demand curve shifts upward and yet the buyer's probability of winning the auction and expected surplus are both decreased. (Analogously, a monopolist may respond to an increase in demand by reducing quantity sold and consumer surplus.)

This recipe in terms of demand and marginal revenue curves is obviously reminiscent of the familiar solution of the third-degree price discrimination problem. Some of the common elements deserve special comment.

1. Because $M R=-\infty$ for all values below the lower end of the support of a buyer's valuation, buyers can never pay less than the lowest values in their distributions. Just as in the standard monopoly problem, if the monopolist knows that no customer has a value less than $\underline{v}$, then even if she should decide to sell to every customer in a market, she still will not charge a price below $\underline{v}$.

2. Just as in the monopoly problem, goods are allocated to buyers in the priority established by their marginal revenues. Just as in the monopoly problem, the price a buyer pays is the lowest value he could have had and still end up buying the good. Finally, no buyer from the part of the demand curve or distribution with negative marginal revenue is ever given a unit, even if the capacity constraint is not binding.

3. Just as in the monopoly price discrimination problem, we have implicitly ruled out resale if someone other than the highest-value buyer wins the auction, ${ }^{4}$ and to avoid the durable goods monopoly

\footnotetext{
${ }^{4}$ In the monopoly context, we usually assume that if resale is possible, the best the seller can do is set the same price in each market-equivalent to running a second-price auction in the auctions case. However, when resale is allowed, the monopoly/auctions analogy fails. The reason is that, with monopoly, we assume that if prices are set differently in different markets so that resale will occur, the resale market will be competitive. In the auctions problem, resale involves a problem of bilateral monopoly.
} 
problem, we have assumed that the seller can make a promise not to hold another auction if there is no sale the first time. The point here is not just to note these major assumptions, but to emphasize that for every assumption we make in one problem, we make a corresponding assumption in the other. For example, our analysis of auctions assumes risk neutrality throughout. The corresponding assumption in the theory of monopoly is that either a monopolist's customers are risk neutral or the monopolist is constrained to simply setting a price in each market (for, if not, standard monopoly pricing does not maximize the profits of a monopolist). This linking of assumptions is a consequence of the mathematical linkage between the monopoly and optimal auctions problems, which we now demonstrate.

\section{Price Discriminating Monopoly and Optimal Auctions ${ }^{5}$}

In this section we first develop an unconventional representation of the third-degree monopoly price discrimination problem. Despite the unfamiliarity of the resulting mathematics, the solution is, of course, just the usual one. We then show that the optimal auctions problem by Myerson can be described by the same objective function and an only slightly different constraint, so the correspondence between the two becomes clear.

Consider a monopolist who sells in $n$ different markets. Each pricetaking consumer in each market is interested in buying at most one unit of the good. Customers in market $i$ have values between $\underline{v}_{i}$ and $\bar{v}_{i}$, with $F_{i}(v)$ customers having a value less than or equal to $v$. Take $F_{i}\left(\bar{v}_{i}\right)$ $=1$, so that the mass of potential consumers in each market is one. Marginal revenue is assumed to be downward sloping in all markets, and the monopolist has constant marginal costs of zero up to a capacity of $\tilde{Q}$ units, where $\tilde{Q}$ is a random variable between $Q$ and $\bar{Q}$ that takes on the value $Q$ with probability $h(Q)$. We assume that the monopolist can set prices (and, implicitly, market quantities) contingent on the realized value of $\tilde{Q}$ and that she seeks to maximize expected profits by her choice of price in each market.

Given that prices can depend on $Q$ we define $p_{i}(v, Q)$ as the proba-

\footnotetext{
Milgrom (1987) discusses auctions with resale and without reservation prices in the case in which all buyers' values are common knowledge. In fact, the no-resale assumption is not necessary in most models with symmetric buyers, such as those of Vickrey (1961) and Riley and Samuelson (1981). However, an implicit no-resale assumption is made in Myerson (1981) and in Milgrom and Weber's (1982) analysis of the "general symmetric case," which treats nonindependent values.

${ }^{5}$ This section is relatively technical and might be skimmed or skipped on first reading.
} 
bility that a buyer in market $i$ with value $v$ will acquire a unit if the monopolist's capacity is $Q$. We shall need this general formulation (with $p$ depending on $Q$ ) in Section $\mathrm{V}$, where we consider marginal revenue curves that are not everywhere downward sloping. However, for now $p_{i}(v, Q)$ is one if the monopolist with capacity $Q$ will set a price less than or equal to $v$ in market $i$ and $p_{i}(v, Q)$ is zero if the monopolist will choose a price above $v$ (as long as buyers act as price takers, which is rational when there is an atomless mass of them, and the monopolist sets prices so that total demand does not exceed $Q$ ). Further, we define

$$
\bar{p}_{i}(v) \equiv \int_{Q}^{\bar{Q}} p_{i}(v, Q) h(Q) d Q
$$

as the unconditional probability that a buyer in market $i$ with value $v$ will get a unit (or equivalently that price will be less than or equal to $v$ ).

Since the expected social value of the units sold is the sum of the buyers' expected consumer surplus and the monopolist's expected revenues, the monopolist can be thought of as maximizing the expected social value of the units sold minus the expected consumer's surplus.

The expected social value of units sold can be written as

$$
\int_{Q}^{\bar{Q}} h(Q) \sum_{i=1}^{n} \int_{\underline{v}_{i}}^{\bar{v}_{i}} v f_{i}(v) p_{i}(v, Q) d v d Q
$$

or, equivalently,

$$
\sum_{i=1}^{n} \int_{\underline{v}_{i}}^{\bar{v}_{i}} v f_{i}(v) \bar{p}_{i}(v) d v
$$

where $f_{i}(v)=d F_{i}(v) / d v>0$ is the number (density) of customers in market $i$ with value $v$. Note that expected unit sales in market $i$ equal

$$
\int_{\underline{v}_{i}}^{\bar{v}_{i}} f_{i}(v) \bar{p}_{i}(v) d v
$$

By noting that a buyer in market $i$ with a value of $\underline{v}_{i}$ will receive zero expected consumer's surplus, since there can never be any incentive to set the price in market $i$ below $\underline{v}_{i}$, we are able to calculate the expected consumer's surplus from a graph such as that in figure 2. In the figure, we consider a simple example of a market in which buyer values are distributed between zero and 100 and in which, with probability .5 , the monopolist charges a price of 50 and, with probability $x$, she charges a price of $100 x$ or less, $.5<x \leq 1$. (This might happen, for 


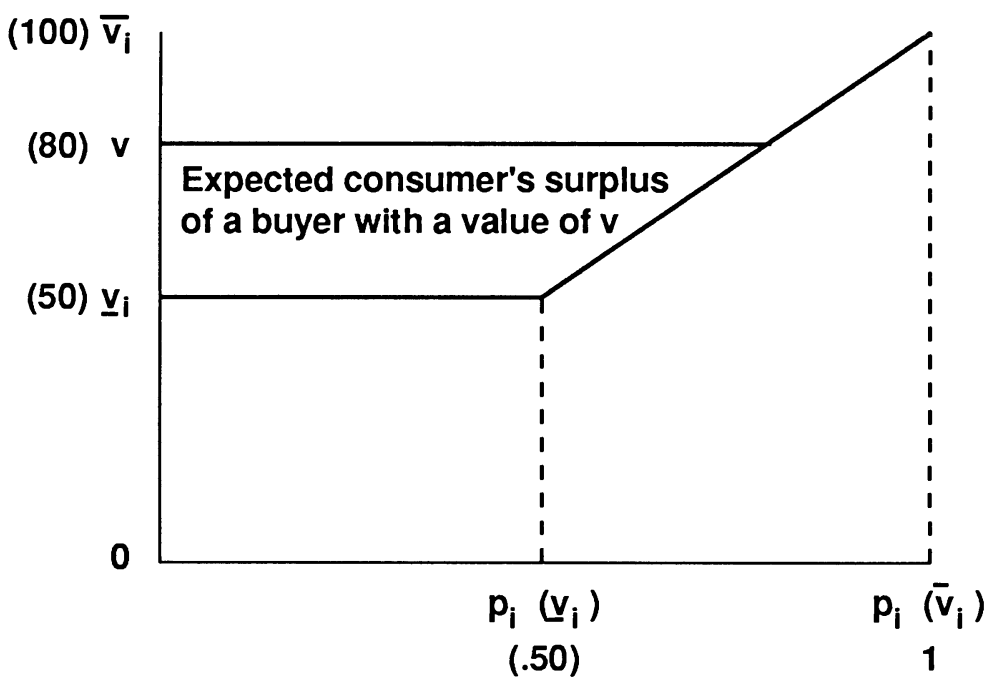

FIG. 2

example, if an optimizing monopolist sold in one market with a demand curve $p_{i}=100-q_{i}$ and the monopolist's capacity was uniformly distributed between zero and 100 .) Thus a buyer with a value of 80 can expect, with probability .5, to buy a unit for 50 and, with probability .3, can expect to buy a unit for a price uniformly distributed between 50 and 80 . So $\bar{p}_{i}(v)$ is zero for $v<50$ and is $.01 v$ for 100 $\geq v \geq 50$. Integrating along the value axis and noting that with one market $\bar{p}_{i}(v)=p_{i}(v)$, we see that a buyer with a value of $v$ has an expected consumer's surplus of $\int_{v_{i}}^{v} \bar{p}_{i}(x) d x$.

Using this formula for the consumer's surplus of a buyer with value $v$, we find that total expected consumer's surplus is

$$
\int_{Q}^{\bar{Q}} h(Q) \sum_{i=1}^{n} \int_{\underline{v}_{i}}^{\bar{v}_{i}} f_{i}(v) \int_{\underline{v}_{i}}^{v} p_{i}(x, Q) d x d v d Q
$$

or, equivalently,

$$
\sum_{i=1}^{n} \int_{\underline{v}_{i}}^{\bar{v}_{i}} f_{i}(v) \int_{\underline{v}_{i}}^{v} \bar{p}_{i}(x) d x d v
$$

The monopolist's revenues can now be written as (2) minus (3):

$$
\sum_{i=1}^{n} \int_{\underline{v}_{i}}^{\bar{v}_{i}} v f_{i}(v) \bar{p}_{i}(v) d v-\sum_{i=1}^{n} \int_{\underline{v}_{i}}^{\bar{v}_{i}} f_{i}(v) \int_{\underline{v}_{i}}^{v} \bar{p}_{i}(x) d x d v,
$$


and her problem becomes one of maximizing (4) subject to the feasibility constraint on sales relative to capacity,

$$
\sum_{i=1}^{n} \int_{\underline{v}_{i}}^{\bar{v}_{i}} f_{i}(v) p_{i}(v, Q) d v \leq Q \quad \forall Q,
$$

by choosing prices in each market or, equivalently, the value at which $p_{i}(v, Q)$ switches from zero to one. This maximization is also subject to the additional conditions that $0 \leq p_{i}(v, Q) \leq 1$ and that $p_{i}$ be nondecreasing in $v$. This latter condition reflects the impossibility of finding a price that will make a higher-valued buyer take a unit less often than a lower-valued buyer in the same market.

We now note two features of (4) and (5) that will give this problem some of the simplicity and familiarity it deserves. First, since the monopolist is allowed to make her allocation rule contingent on $Q$ we can solve the optimization problem separately for each $Q$. Therefore, we can simply maximize

$$
\pi(Q)=\sum_{i=1}^{n} \int_{\underline{v}_{i}}^{\bar{v}_{i}} v f_{i}(v) p_{i}(v, Q) d v-\sum_{i=1}^{n} \int_{\underline{v}_{i}}^{\bar{v}_{i}} f_{i}(v) \int_{\underline{v}_{i}}^{v} p_{i}(x, Q) d x d v
$$

subject to

$$
\sum_{i=1}^{n} \int_{\underline{v}_{i}}^{\bar{v}_{i}} f_{i}(v) p_{i}(v, Q) d v \leq Q
$$

Second, defining $z(v, x)$ to be zero for $x>v$ and one for $x \leq v$, we can rewrite the last term in $\left(4^{\prime}\right)$ by noting that

$$
\begin{aligned}
\int_{\underline{v}_{i}}^{\bar{v}_{i}} f_{i}(v) \int_{\underline{v}_{i}}^{v} p_{i}(x, Q) d x d v & =\int_{\underline{v}_{i}}^{\bar{v}_{i}} \int_{\underline{v}_{i}}^{\bar{v}_{i}} f_{i}(v) p_{i}(x, Q) z(v, x) d x d v \\
& =\int_{\underline{v}_{i}}^{\bar{v}_{i}} p_{i}(v, Q) \int_{v}^{\bar{v}_{i}} f_{i}(x) d x d v \\
& =\int_{\underline{v}_{i}}^{\bar{v}_{i}}\left[F_{i}(\bar{v})-F_{i}(v)\right] p_{i}(v, Q) d v \\
& =\int_{\underline{v}_{i}}^{\bar{v}_{i}}\left[1-F_{i}(v)\right] p_{i}(v, Q) d v .
\end{aligned}
$$

With this substitution, expected revenues (4') can be expressed as

$$
\mathrm{ER}=\sum_{i=1}^{n} \int_{\underline{v}_{i}}^{\bar{v}_{i}}\left[v-\frac{1-F_{i}(v)}{f_{i}(v)}\right] f_{i}(v) p_{i}(v, Q) d v .
$$


However, the expression in brackets is just $\mathrm{MR}_{i}(v)$. Therefore, expected revenues are

$$
\sum_{i=1}^{n} \int_{\underline{v}_{i}}^{\bar{v}_{i}} \operatorname{MR}_{i}(v) f_{i}(v) p_{i}(v, Q) d v,
$$

and, subject to the constraints, the seller wants to select the $p_{i}$ functions to maximize the expected marginal revenues of those receiving the good.

Since $f_{i}(v)>0$ enters in both the objective and the constraint linearly and both are linear in $p_{i}(v, Q)$, the solution is clear: put as much weight as possible $\left(p_{i}(v, Q)=1\right)$ on high values of $\operatorname{MR}_{i}(v)$ and none on low values. Since $M_{i}$ is assumed increasing, the constraint $\partial p_{i}(v, Q) / \partial v \geq 0$ is not binding. So for each $Q$, the monopolist should (1) sell to all buyers in each market for whom $\operatorname{MR}_{i}(v) \geq 0$ if the quantity constraint $\left(5^{\prime}\right)$ is not binding and (2) if the constraint is binding, allocate units to the buyers with the highest marginal revenues, by choosing prices to equate the marginal revenues of the lowestvalued buyers actually supplied in each market.

We shall now show that the optimal auctions problem solved by Myerson (1981) is virtually identical to this formulation of the monopoly problem. In the auction context, $n$ is the number of bidders rather than the number of markets, and $F_{i}(v)$ is the probability that buyer $i$ 's value is less than $v$ rather than the number of buyers in market $i$ with values below $v$. Furthermore, in the auctions case the probability that a buyer with value $v$ in market $i$ will win the auction must be written as a function $p_{i}\left(v_{1}, \ldots, v_{n}\right)$ of the values of all the bidders rather than as a function of his value and the quantity sold. However, defining $\bar{p}_{i}(v)$ for the auctions problem as $E\left(p_{i}\left(v_{1}, \ldots, v_{i-1}, v, v_{i+1}, \ldots, v_{n}\right)\right)$, we still have $\bar{p}_{i}(v)$ as the unconditional probability that the buyer with distribution $F_{i}$ (from market $i$ ) will receive the good, just as in the monopoly problem.

Defining $S_{i}(v)$ as the expected surplus of the $i$ th bidder if his value is $v$, Myerson notes that equilibrium in the game induced by any set of action rules requires that

$$
\frac{\partial S_{i}(v)}{\partial v}=\bar{p}_{i}(v) \geq 0 .
$$

The reason is that a buyer with a value of $v+d v$ can achieve at least the surplus of a buyer with a value of $v$, plus $\bar{p}_{i}(v) d v$, simply by imitating the bidding strategy of a buyer with a value of $v$. Similarly, a buyer with a value of $v$ can achieve at least $S_{i}(v+d v)-\bar{p}_{i}(v+d v) d v$. Therefore, surplus must be increasing in $v$ at a rate of $\bar{p}_{i}(v)$ in order to 
induce correct revelation of values, while the revelation principle means that correct revelation can be assumed to be induced.

Equation (8) implies that buyers with lower values will have lower surpluses, so the lowest surplus in any market $i$ will be achieved by a buyer with value $\underline{v}_{i}$. Since the seller's expected revenue is the expected value of the good to the auction winner less expected surplus, under the optimal auction the seller will obviously set $S_{i}\left(\underline{v}_{i}\right)=0$, the lowest value possible. Therefore, the surplus to a buyer $i$ with value $v, S_{i}(v)$, equals

$$
0+\int_{\underline{v}_{i}}^{v}\left[\frac{\partial S_{i}(x)}{\partial x}\right] d x=\int_{\underline{v}_{i}}^{v} \bar{p}_{i}(x) d x
$$

just as in the monopoly problem. Total expected consumer's surplus can be written then as (3), if we bear in mind that $\bar{p}_{i}\left(v_{i}\right)$ is now the expected value over $v_{-i} \equiv\left(v_{1}, \ldots, v_{i-1}, v_{i+1}, \ldots, v_{n}\right)$ of $p_{i}\left(v_{1}, \ldots, v_{n}\right)$. Myerson's objective function in the optimal auctions problem is then just (4) or, equivalently, (7), precisely as in the monopoly problem.

The seller in an auction maximizes (4) or (7) subject to the capacity constraint

$$
\sum_{i=1}^{n} p_{i}\left(v_{1}, v_{2}, \ldots, v_{n}\right) \leq 1
$$

which says that the seller cannot promise to deliver more than one unit. Again, there are also constraints that $0 \leq p_{i}\left(v_{1}, v_{2}, \ldots, v_{n}\right) \leq 1$ and $\partial p_{i}\left(v_{1}, \ldots, v_{n}\right) / \partial v_{i} \geq 0$. The second arises because it is impossible to design a mechanism (pick $p_{i}$ functions) that will make a buyer follow a strategy that leads to a lower probability of winning the auction when he has a higher value. In any given mechanism, buyers trade off raising their probability of receiving a good against raising expected payments. If a low-value buyer finds it worth paying some extra amount to raise the probability of receiving the good, then a highvalue buyer, whose higher valuation makes the increased probability even more valuable, would certainly do so as well. Therefore, if all types of buyers maximize utility, a higher-value type will always choose a strategy that leads to at least as high a probability of receiving the good as a lower-value type.

Thus the mathematical problem facing the auction designer is essentially equivalent to the monopolist's problem. There are two differences: in the monopoly problem the choice variables are the probabilities $p_{i}\left(v_{i}, Q\right)$, while those in the monopoly problem are $p_{i}\left(v_{1}, \ldots\right.$, $\left.v_{n}\right)$; the capacity constraint in the monopoly problem is

$$
\sum \int f_{i}\left(v_{i}\right) p_{i}\left(v_{i}, Q\right) d v_{i} \leq Q,
$$


while the corresponding constraint in the auctions problem is $\sum p_{i}\left(v_{1}, \ldots, v_{n}\right) \leq 1$. Note, however, that even these differences are less than what might appear. First, the arguments of the $p_{i}$ functions other than $v_{i}$-namely, $Q$ and $v_{-i}$-are both random variables distributed independently of $v_{i}$. Second, when we consider $p_{i}$, these variables can be taken as given and known: $Q$ by assumption and $v_{-i}$ because the other agents will be induced to reveal their valuations correctly. Third, as noted, both constraints bear a capacity interpretation. In fact, the only important difference is the absence of the $f_{i}(v)$ in the auction constraint. But even this does not change the nature of the solution.

To solve the auction problem, substitute in (4) as above to obtain

$$
\sum_{i=1}^{n} \int_{\underline{v}_{i}}^{\bar{v}_{i}} \operatorname{MR}_{i}(v) f_{i}(v) \bar{p}_{i}(v) d v
$$

and now write this as

$$
\sum_{i=1}^{n} \int_{\underline{v}_{1}}^{\bar{v}_{1}} \ldots \int_{\underline{v}_{n}}^{\bar{v}_{n}} \operatorname{MR}_{i}\left(v_{i}\right) f_{1}\left(v_{1}\right) \ldots f_{n}\left(v_{n}\right) p_{i}\left(v_{1}, \ldots, v_{n}\right) d v_{1} \ldots d v_{n} .
$$

This formulation makes clear the linearity of the objective function in $p_{i}$.

Thus the expected contribution to profit from increasing the probability of allocating the good to buyer $i$ whenever the vector of buyer values is $\left(v_{1}, \ldots, v_{n}\right)$ is the probability that buyers will have exactly those values, $\Pi_{i=1}^{n} f_{i}\left(v_{i}\right)$, times $\operatorname{MR}_{i}$. Combined with (9), this obviously means that, for each vector $\left(v_{1}, \ldots, v_{n}\right)$, profits are maximized by allocating the good to the highest marginal revenue bidder with probability one in all cases, as long as the highest marginal revenue is greater than zero. As in the monopoly problem, $\operatorname{MR}_{i}\left(v_{i}\right)$ is independent of the $p$ functions and of the values of any bidder other than $i$.

Finally, we note that the derivation leading to $(10)$ is valid for all mechanisms that meet incentive compatibility and participation constraints, regardless of whether such a mechanism is optimal. The participation constraints' being binding was used only in showing $S_{i}\left(\underline{v}_{i}\right)=0$. The implication is that the expected revenue from any mechanism can be written as

$$
\begin{aligned}
\mathrm{ER} & =\sum_{i=1}^{n} \int_{\underline{v}_{i}}^{\bar{v}_{i}} \operatorname{MR}_{i}(v) f_{i}(v) \bar{p}_{i}(v) d v-K \\
& =\text { expected MR of winning bidder }-K,
\end{aligned}
$$

where $K$ is the sum of the expected surpluses of the $n$ bidders if each had the lowest value in the support of his distribution. Obviously a 
monopolist or auction seller will never choose to give buyers with the minimum possible value any consumer surplus, and so he will set $K=$ 0 . If we restrict ourselves to mechanisms for which $K=0$, as we shall do for the remainder of the paper, it is clear from (11) that any mechanism is an optimal auction mechanism if it always allocates the good to the bidder with the highest positive marginal revenue, with no sale occurring when all bidders have negative marginal revenues.

Note that this solution does not specify how to charge for the good in the auction, just how to assign it. Of course, whatever method is used to determine payments must meet the incentive and participation constraints, so that each bidder will report his value honestly and will participate no matter what his value. One such is the system discussed before of charging the lowest value that the winner could have announced and still have had the highest positive marginal revenue: it gives expected surplus of zero to a bidder with value $v_{i}=\underline{v}_{i}$, each bidder's expected surplus is an increasing function of his valuation, and, as argued above, it has the property that no one can gain by misrepresentation. However, we shall see in the next section that there may be other optimal payment schemes.

To summarize, just as in the monopoly problem, the seller in the auction has an objective function that can be interpreted as maximizing the expected marginal revenue of the consumers who receive units subject to a capacity constraint. Just as in monopoly, the problem is solved by allocating the unit(s) to the buyer(s) with the highest marginal revenue(s). Finally, the solutions to the two optimization problems are similar: in both, units are allocated to buyers with priority based on marginal revenue until either quantity is exhausted or there are no buyers left with positive marginal revenue.

One other essentially technical point remains: Because we assumed that marginal revenue was downward sloping in quantity within each market, we could be sure that if the monopolist wants to sell to a particular buyer in any given market, she should also want to sell to all higher-value buyers. What if marginal revenue is not downward sloping? According to the current setup of the problem, one would like to sell to some buyers with a lower value but higher marginal revenue before other buyers with higher values but lower marginal revenues. But higher-value buyers will always be willing to buy whenever lowervalue buyers want to buy, so it is impossible to make the probability that a high-value buyer will acquire a good less than the probability that a low-value buyer will acquire the good. Mathematically, if marginal revenue is not always downward sloping, the constraint that $\partial \bar{p}_{i}(v) / \partial v \geq 0$ becomes binding. This constraint is the concern of Section VI, where we explain what Myerson calls the "general case." 


\section{Revenue Equivalence}

We are now ready to explore further the single most important result in Myerson's paper, the calculation of the expected revenue from the optimal-or any other-auction. This result in turn yields a strong revenue equivalence result.

Consider a monopolist with a random capacity constraint who sells in several markets. Then, as shown in the preceding section, regardless of what algorithm the monopolist uses for determining prices ${ }^{6}$ (and therefore quantities) in each market as a function of total available quantity, expected revenue can be written as

$$
\mathrm{ER}=\sum_{i=1}^{n} \int_{\underline{v}_{i}}^{\bar{v}_{i}} \operatorname{MR}_{i}(v) f_{i}(v) \bar{p}_{i}(v) d v
$$

where $\bar{p}_{i}(v)$ is the probability that a buyer in market $i$ with value $v$ will be assigned a unit of the good and $f_{i}(v)$ is the density of buyers in market $i$ with value $v$. That is, expected revenue can be found by summing, over all buyers in all markets, the marginal revenue of each buyer times the probability that the buyer will receive a unit. (When probabilities are all one and zero, this is just saying that total revenue is the sum of the marginal revenues of all units sold.) This formula, which is just (7) averaged over all possible quantity constraints, holds regardless of whether the monopolist optimizes or not.

Another way of restating (12) is that expected revenue equals the expectation of the product of the number of sales and the average marginal revenue of those who buy. For auctions we think of the seller as a buyer with a marginal revenue of zero. This implies that the number of sales is always one and the average marginal revenue of those who buy is just the marginal revenue of the one winning bidder. Therefore, we can interpret (12) as saying that the expected revenue from any feasible auction is the expected marginal revenue of the winning bidder.

This formula is central. Most obviously, it makes clear why the optimal auction gives the good to the bidder with the highest marginal revenue. Moreover, it carries immediate implications for comparing expected revenues across auctions.

If the winner under one such auction rule is also the winner under a second auction rule, then the two auctions will yield the same expected revenue. Therefore, with symmetric buyers, first- and second-

\footnotetext{
${ }^{6}$ Provided she never charges any buyer less than the lowest value he could possibly place on the good. The corresponding qualification in interpreting this equation in the auction context, which we shall do below, is that each bidder $i$ receive zero expected surplus when $v_{i}=\underline{v}_{i}$.
} 
price auctions always yield the same expected revenue: since the bidder with the highest value will always win in both auctions, the expected marginal revenue of the winning bidder is the same in both. It is also clear that the optimal reservation price occurs when $M R=0$ for each buyer and that this reservation price is independent of the number of bidders. Furthermore, any mechanism that always awards the good to the highest marginal revenue buyer (including the seller as a buyer with $M R=0$ ) yields the same expected revenue. Therefore, such a mechanism is optimal. For symmetric bidders, both firstand second-price auctions with appropriately chosen reservation prices are optimal, provided marginal revenue is downward sloping.

If buyers are not symmetric, then first- and second-price auctions will not always have the same winner because sometimes a lowervalued buyer can win a first-price auction, while the highest-valued bidder always wins under the second-price auction. Therefore, expected revenues are also generally different. While neither auction is optimal, whether a first-price or second-price auction will have higher expected revenue for asymmetric buyers depends on whether, when a buyer wins the first-price auction without having the highest value, that buyer on average has a higher or lower marginal revenue than the buyer with the highest value.

\section{Optimal Auctions in the General Case: "Ironing Out" the Marginal Revenue Curve}

In this section we deal with the technical problem of how to design an optimal auction when $v-\left\{\left[1-F_{i}(v)\right] / f_{i}(v)\right\}$ is not necessarily monotonic. Myerson's solution of this general case again turns out to be equivalent to the solution to the monopoly problem when marginal revenue is not downward sloping. We begin by discussing this latter problem.

Consider a conventional monopolist whose marginal revenue curve is not always downward sloping. For example, figure 3 graphs the marginal revenue curve for a monopolist facing a demand curve $p=$ $100-2 q$ for $0 \leq q \leq 20$ and $p=70-.5 q$ for $20 \leq q \leq 100$. Then MR $=100-4 q$ for $0 \leq q \leq 20$ and jumps discontinuously to $\mathrm{MR}=70-$ $q$ for $q>20$.

Suppose that the firm has constant marginal costs. In our numerical example, if costs exceed 50 per unit or are less than 20 per unit, the monopolist's problem is simple: There is only one point at which MR $=\mathrm{MC}$. However, if costs are in the midrange, the problem is harder. In figure 3 , where we assume constant marginal costs of 40 , the monopolist would like to collect the marginal revenue of the first 15 buyers, who have values greater than 70 and marginal revenues 


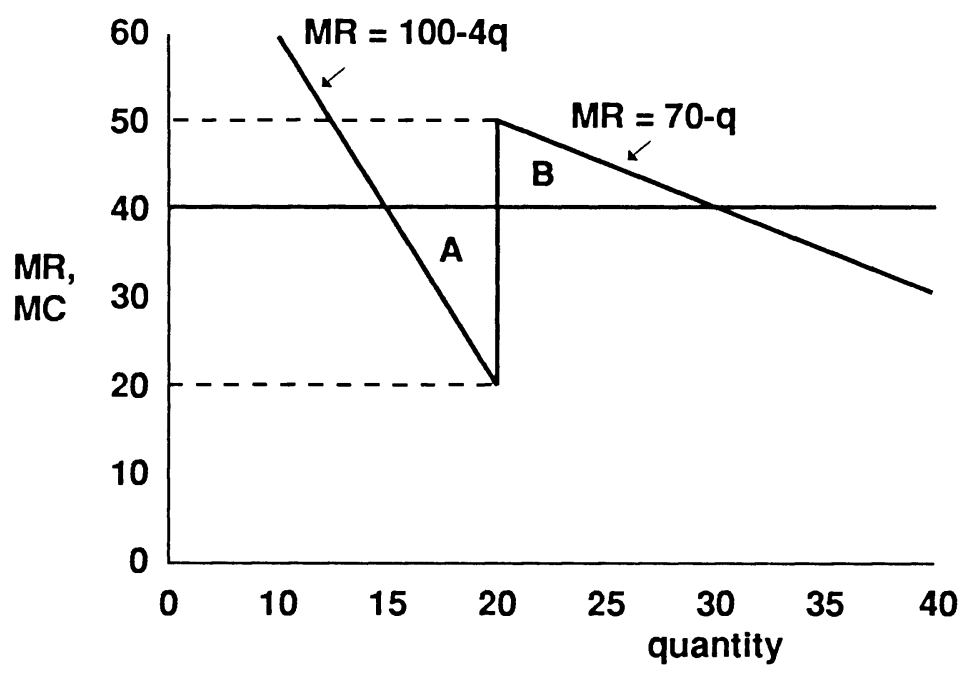

Fig. 3.- "Ironing" a marginal revenue curve

greater than 40, skip the next five buyers with values between 70 and 60 and marginal revenues between 40 and 20, and then sell to the buyers with values between 60 and 55 and marginal revenues between 50 and 40 . Unfortunately, it is impossible to devise a mechanism in which a buyer with a value between 55 and 60 will receive a good more often than a buyer with a value between 60 and 70 . In terms of Section IV, we face a constraint that $\partial p_{i} / \partial v \geq 0 .{ }^{7}$

In the case of figure 3, the losses on units 15-20 (area $A$ ) exactly equal the profits on units 20-30 (area $B$ ). So the monopolist with constant marginal costs of 40 is indifferent to selling 15 units at a price of 70 or 30 units at a price of 55 . If costs were greater than 40 , area $A$ would be greater than $B$ and the firm would produce less than 15; with costs less than 40 , the firm would produce more than 30 units. So the firm operates as though it is facing an "ironed-out" marginal revenue curve that has $\mathrm{MR}=40$ for $15 \leq q \leq 30 .^{8}$

What if the firm has zero marginal costs up to 20 units and then hits a capacity constraint? Ideally, the monopolist would like to sell to the 14 buyers with the highest reservation prices, skip six buyers, and then sell to the next six. However, this is impossible because of the $\partial p_{i} / \partial v \geq 0$ constraint. The best the monopolist can do is sell to the top

\footnotetext{
${ }^{7}$ Myerson establishes this condition as a necessary condition for obtaining correct revelation.

${ }^{8}$ If marginal costs equaled 40, a monopolist facing the ironed marginal revenue curve would be indifferent to selling any quantity between 15 and 30 . A firm facing the marginal revenue curve in fig. 3 will also be indifferent to any quantity from 15 to 30 , but only if it uses the lottery procedure described in the next two paragraphs.
} 
15 buyers and give all the buyers on the ironed part of the marginal revenue curve a $1 / 3$ chance of receiving a unit, through a lottery, which will make the shadow value to the monopolist of the last five units equal to the ironed marginal revenue of 40 , times five. ${ }^{9}$

The seller wishes to sell to the top 15 buyers and give each of the next 15 a $1 / 3$ chance of buying. She therefore gives buyers a choice: either participate in a lottery or pay a higher price and acquire a unit for sure. In order to attract the thirtieth-highest-valued buyer into the lottery, a winner of the lottery must be given a unit for his value of $v$ $=70-.5(30)=55$. The price of getting a unit for sure must be just low enough so that the fifteenth buyer, with a value of 70 , will decide to buy. That buyer can have an expected surplus of $1 / 3(70-55)=5$ from entering the lottery since $5 / 15$ of all lottery participants will win. Therefore, he must be offered a certain unit at a price of 65 to guarantee the same surplus.

By running this lottery, the monopolist earns $65 \times 15+55 \times 5=$ 1,250 versus $60 \times 20=1,200$ if she just charges a market-clearing price of 60 . The difference of 50 (area $A$ in fig. 3) is just the difference, for $q=20$, of the area under the ironed marginal revenue curve and above the original marginal revenue curve.

Myerson's analysis of optimal auctions in the general case allows for the possibility that marginal revenue is not downward sloping. His solution irons the marginal revenue curve for each buyer just as above, although the exposition is in terms of the total revenue as a function of $v$ rather than marginal revenue as a function of $q$.

With ironed marginal revenue curves, there is some probability that one or more of the top two buyers will be on the ironed part of the curve. For example, consider an auction with symmetric buyers, for each of whom $F(v)=.02(v-20), 20 \leq v \leq 60$, and $F(v)=.5+.005 v$ for $60 \leq v \leq 100$. In terms of our analogy, each of these buyers has a demand curve identical to the one in figure 3 , with quantities multiplied by .01 . Buyers with values between 55 and 70 would then be on the ironed segment. If both buyers' values put them on the ironed part, Myerson specifies that a lottery occur, with the winner of the lottery paying the equivalent of 55 in the example above.

If only the second-highest marginal revenue bidder is on the flat part of the curve, the bidder with the highest marginal revenue pays a price that would have made the lowest-value buyer on the part of the marginal revenue curve before the flat (the buyer with the value of 70 in our example) indifferent to buying and participating in a lottery.

\footnotetext{
${ }^{9}$ The reader should be able to confirm that changing the lottery to average over more or less than the 15 buyers on the ironed part of the marginal revenue curve will reduce the average marginal revenue of the lottery participants.
} 
Note that while Myerson specifies that the lotteries be "fair," there is no need for this: The auctions lottery could always award the good to the buyer whose name came first in the alphabet, a system Bulow likes better than Roberts. Because the ironed marginal revenue of all buyers who enter a lottery is the same, discrimination among these buyers does not alter either the expected (ironed) marginal revenue of the winning bidder or the expected revenue from the auction. ${ }^{10}$

\section{Bilateral Exchange with Private Values}

The solution methods developed in the optimal auctions literature are widely applicable to problems involving private information. In this section we illustrate how the marginal revenue/marginal cost logic developed above can make the solution to such problems more intuitive. We focus on the problem of social efficiency in bilateral monopoly when both the buyer's and the seller's valuations for the object are private information.

Note that the "optimality" of optimal auctions relates to the maximization of seller surplus rather than social efficiency. ${ }^{11}$ However, designing a socially efficient auction mechanism when the seller's value is known is easy: a second-price auction with a reservation price equal to the seller's value does the trick, and if both seller and buyer values are known, then even the mechanism that is privately optimal for the seller (essentially charging the highest-valued buyer his full value, assuming that it exceeds the seller's value) will be socially efficient. However, when both buyer and seller values are private knowledge and it is unclear whether gains from trade exist, it is not possible to design a mechanism that results in transfer of the good exactly when the gains from trade are positive. This result was first shown by Myerson and Satterthwaite (1983). In this section we use the logic developed earlier to derive both their impossibility result and their mechanism for maximizing expected gains from trade subject to the constraints arising from the private information about values and the concomitant opportunities to misrepresent them strategically.

Assume that a single buyer has a value, $v$, drawn from a distribution $F(v), F(v)=0, F(\bar{v})=1, d F / d v=f(v)>0$, for $v \leq v \leq \bar{v}$. The potential seller has a value, $s$, drawn independently from a distribution $G(s)$,

\footnotetext{
${ }^{10}$ It should be noted that Pratt and Zeckhauser (1986) treat precisely this problem in the monopoly context and present the ironing procedure. Earlier, Mussa and Rosen (1978) were the first to fully develop the ironing procedure for marginal revenue in their analysis of product quality. And Hotelling (1931), in discussing monopoly in exhaustible resources, also did a numerical example of ironing a marginal revenue curve, although he did not use the then-new terminology of "marginal revenue."

${ }^{11}$ We should note, however, that in Vickrey's original work he was primarily concerned with issues of social efficiency.
} 
also on $[\underline{v}, \bar{v}]$, with $d G / d S=g(s)>0$ for $\underline{v} \leq s \leq \bar{v}$. That is, the range of possible values is the same for the buyer and seller. Gains from trade may or may not be possible, depending on the actual values of $s$ and $v$. Is there any mechanism that can guarantee ex post efficient trade, and, if not, how can expected gains from trade be maximized?

The problem of whether an efficient mechanism exists is most easily solved by creating a fictitious, risk-neutral broker whose job it is to maximize expected profits subject to the constraint of having trade take place if and only if $v \geq s$. If the expected profit-maximizing mechanism, which maximizes expected buyer payments less expected seller receipts, yields negative expected profits, then clearly the buyer and seller cannot achieve efficiency on their own (e.g., without a subsidy from some third party).

The broker's job is considerably simplified by her ability to choose mechanisms that make the buyer's payment contingent on the seller's value and similarly make the seller's revenue contingent on the buyer's value, while ensuring that both are reported correctly. Therefore, the broker can solve separately the problems of maximizing expected revenue subject to efficiency constraints contingent on knowing the seller's value, and minimizing expected payments to the seller contingent on knowing the buyer's value, with the broker's profit being the difference between buyer payments and seller receipts.

From (4') we find that the broker's objective function when faced with one buyer can be written as

$$
\max \int_{\underline{v}}^{\bar{v}} v f(v) p(v, s) d v-\int_{\underline{v}}^{\bar{v}} f(v) \int_{\underline{v}}^{\bar{v}} p(x, s) d x d v
$$

or, equivalently from (7),

$$
\max \int_{\underline{v}}^{\bar{v}} \operatorname{MR}(v) f(v) p(v, s) d v,
$$

where

$$
\operatorname{MR}(v)=v-\frac{1-F(v)}{f(v)}
$$

subject to the efficiency constraints

$$
\begin{array}{ll}
p(v, s)=1 & \text { if } v \geq s, \\
p(v, s)=0 & \text { if } v<s .
\end{array}
$$

The constraint that trade must always and only occur when the buyer's value equals or exceeds the seller's renders the maximization 
trivial. Simply put, if the seller's value is $s$, the broker can do no better than offer the good to the buyer at a take-it-or-leave-it price of $s$, thereby giving the buyer all the gains from trade.

But the broker must also induce the seller to sell whenever $s \leq v$. If we regard the broker as a monopsonist relative to the seller in the same way she is a monopolist relative to the buyer, the broker's problem with the seller is to minimize

$$
\int_{\underline{v}}^{\bar{v}} \operatorname{MC}(s) g(s) p(v, s) d s,
$$

where

$$
\mathrm{MC}(s)=s+\frac{G(s)}{g(s)}
$$

subject to

$$
\begin{array}{ll}
p(v, s)=1 & \text { if } s \leq v, \\
p(v, s)=0 & \text { if } s>v .
\end{array}
$$

The simplest-and essentially the only-way of meeting the efficiency constraint of having the seller agree to sell whenever $s \leq v$ is to offer the seller a take-it-or-leave-it price equal to $v$, giving all the gains from trade to the seller.

Combining the buyer and seller results, we find that the broker must give each party all the gains from trade. To do this, the broker must run a loss equal to the expected gains from trade, implying that a subsidy of like amount is required if efficiency is to be achieved.

Thus ex post efficiency cannot be achieved in bilateral trade with private information on both sides if the buyer's and seller's ranges of possible values coincide. Further, generalization to the case of overlapping but not identical ranges for buyer and seller values is simple. If buyers can have values as high as $\bar{b}>\bar{v}$, the highest possible value for $s$, we know that all such buyers will have to be treated like buyers of value $\bar{v}$ : they can always imitate those buyers, who will receive the good with probability one, and so there is no way to prevent such mimicry. Similarly, if sellers can have values as low as $\underline{s}<\underline{v}$, all sellers with values $s<\underline{v}$ are indistinguishable, for the purpose of this analysis, from sellers with values $\underline{v}$.

If full ex post efficiency is unattainable, what then is the best that can be done?

The mechanism that maximizes efficiency subject to a feasibility constraint is derived in two parts. First, we find the most efficient mechanism that gives the broker zero expected profits. Second, stan- 
dard mechanism design tricks are used to create an equivalent mechanism that yields the broker zero actual (rather than expected) profits, allowing the buyer and seller to dispense with the broker altogether.

Expected gains from trade can be written as

$$
\int_{\underline{v}}^{\bar{v}} \int_{\underline{v}}^{\bar{v}}(v-s) f(v) g(s) p(v, s) d v d s .
$$

Combining (13), which gives the buyer's expected payments, and (16), which gives the seller's expected receipts, yields an expected profit constraint of the form

$$
\int_{\underline{v}}^{\bar{v}} \int_{\underline{v}}^{\bar{v}}[\operatorname{MR}(v)-\operatorname{MC}(s)] f(v) g(s) p(v, s) d v d s \geq 0 .
$$

This inequality was obtained by Myerson and Satterthwaite as necessary and sufficient for optimality of a mechanism that calls for trade with probability $p(v, s)$.

The problem of solving (19) subject to (20) is just a simple Ramsey pricing problem. The solution is familiar: specify first that trade will occur whenever MR $>$ MC. For cases in which $\mathrm{MR}<\mathrm{MC}$, assign priority based on the ratio of $(v-s) /(\mathrm{MC}-\mathrm{MR})$ ("efficiency" gained to "profits" lost). Allow trade in as many cases as possible using this priority scheme up to the point at which (20) equals zero. ${ }^{12}$ A dominant strategies mechanism that achieves the result begins by specifying that trade will occur when and only when the ratio of $(v-s) /(\mathrm{MC}$ - MR) exceeds the critical level corresponding to (20) equal to zero. Each participant is asked to reveal his or her true value. If trade does not occur, no money changes hands. If trade occurs, the buyer pays the minimum value he could have announced, given the seller's value, for trade to have occurred. Similarly, if trade occurs, the seller receives the maximum value she could have announced, given the buyer's value, for trade to have occurred. Note that, no matter what the values of $v$ and $s$, both the buyer and the seller receive nonnegative surplus, so the participation constraint is met. Further, nowfamiliar arguments show that correct revelation is a dominant strategy for each party, so the incentive constraints are also met.

Note that if we have chosen $p(v, s)$ in such a way that $(20)$ equals zero, the expected receipts of the seller exactly equal the expected payments of the buyer. However, there is no guarantee that actual

\footnotetext{
${ }^{12}$ If the distributions of buyer and seller valuations are not "well behaved" so that marginal revenue and marginal cost curves are not downward and upward sloping, respectively, we must use an ironing technique similar to that employed in Sec. V.
} 
receipts and payments are equal for all $v$ and $s$. Thus we still must go from this mechanism to one in which actual seller receipts equal actual buyer payments.

To do this, we create another game with a Bayesian Nash equilibrium outcome that is the same as the equilibrium in the dominant strategies game. We have the buyer write down his expected payment in the dominant strategy game, inferring his value from what he writes. Similarly, the seller writes down her expected receipts, and we infer her value from what she writes. Finally, we calculate the expected receipts of the seller unconditional on her value, which equals the expected payments of the buyer unconditional on his value.

Our new mechanism specifies payments by the buyer equal to what the buyer has written plus what the seller has written, less the unconditional estimate of payments/receipts. The good is transferred whenever the inferred buyer and seller values would imply trade in the earlier game. Note that the expected payments of any buyer are exactly those in the game with dominant strategies, since from his point of view the expectation of the seller's expected receipts conditional on the seller's value equals the unconditional estimate of the seller's receipts. The same reasoning for the seller implies that both parties will have the same expected payoffs from any announcement of their value that they have in the game with dominant strategies, provided that the other party always truthfully reveals his or her value. Therefore, buyers and sellers announce the same values as in the dominant strategies game, and we have created a mechanism that maximizes efficiency subject to the constraint that buyer payments equal seller receipts.

An example of a mechanism that meets the requirements of this section was given by Chatterjee and Samuelson (1983) for the case in which both buyer and seller have values drawn from the same uniform distribution. Have each write down a price. If the seller asks for more than the buyer bids, no trade occurs. Otherwise, trade occurs at the average of the bid and ask prices. In this uniform and identical distribution case, the Chatterjee-Samuelson mechanism leads to the identical payoffs and outcomes as the revelation mechanism described in the last few paragraphs.

\section{Conclusion}

We have shown how some of the central results of the theory of markets under incomplete information can be interpreted and understood in terms of familiar microeconomic theory. We hope and expect that this will both broaden the impact of these results and lead to a better understanding of other problems of this nature. 


\section{Appendix}

\section{Revenue Equivalence in Auctions with Symmetric Bidders}

This Appendix focuses on a graphical treatment of the results of Vickrey (1961) discussed in Section I. We begin by analyzing a second-price auction. The dominant strategy for each bidder is to bid his true value. This is because a buyer's altering his bid from its true value, $v$, has no effect on whether he wins and what he pays, except in two cases, and in these it is harmful. In the first case, the highest other bid, $b$, exceeds $v$ and the buyer bids more than $b$. Then he gets a surplus of $v-b<0$ instead of the zero he would have gotten from bidding $v$. In the second, $b$ is less than $v$ and the buyer underbids by enough that his bid is less than $b$. Then he gets zero surplus instead of $v-b>$ 0 . Therefore, over- or underbidding can reduce but cannot increase a buyer's surplus.

Given correct revelation, the expected payments and profits of a bidder in a second-price auction can be seen in figure A1. This figure graphs a bidder's possible valuation of the auctioned good against the likelihood of winning the auction. In the special case in which there are only two bidders, each with values independently and uniformly distributed between zero and 100, the curve becomes a straight line from $(0,0)$ to $(1,100)$. With symmetric bidders, a bidder with value $v$ will win the auction whenever his value is highest, and that will occur with probability $[F(v)]^{n-1} \equiv F^{n-1}(v)$; that is, the probability that that bidder will win is the probability that the other $n-1$ bidders will all have a value of $v$ or less. In the numerical example, a bidder with a value of $v$ will have a probability of winning of $.01 \mathrm{v}$.

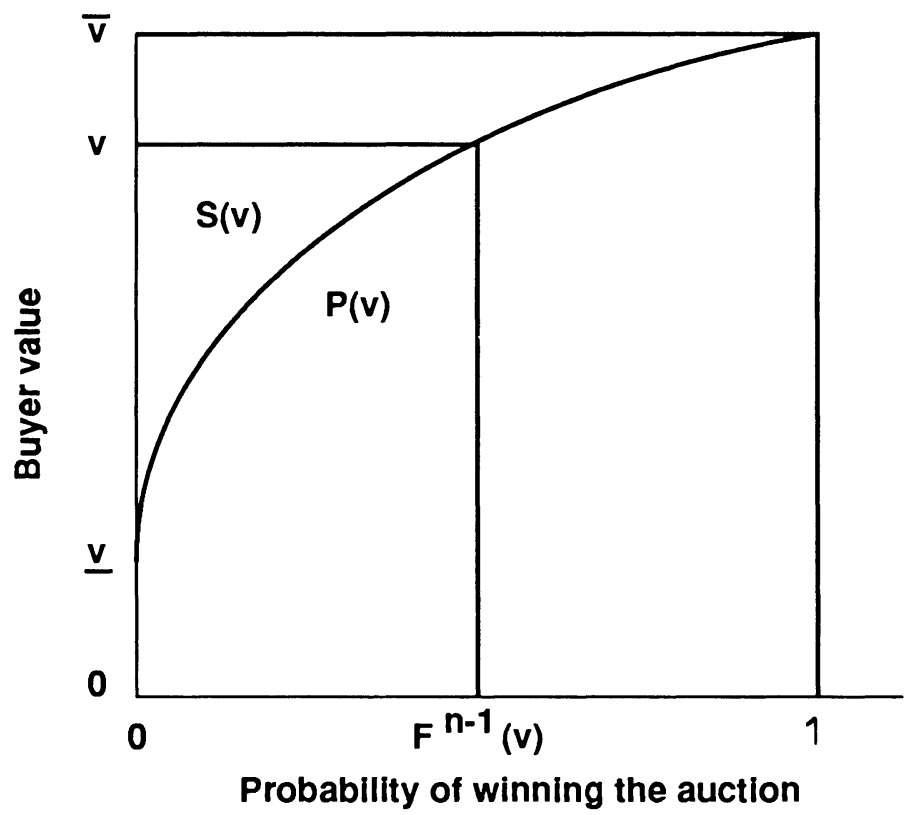

FIG. Al 
With each bidder bidding his true value, the expected payment of a bidder with value $v$ is

$$
\int_{\underline{v}}^{v} x d F^{(n-1)}(x)=v F^{n-1}(v)-\int_{\underline{v}}^{v} F^{n-1}(x) d x,
$$

that is, the area $P(v)$ in figure $\mathrm{A} 1$. The expected payment contingent on winning is the expected second-highest value contingent on $v$ being highest, $B(v) \equiv$ $P(v) / F^{n-1}(v)$. In the numerical example, if $v=80$, the bidder will win the auction with a probability of $.8\left(F^{n-1}(v)=.8\right)$, pay an average of $40(B(v)=$ 40) when he wins, and make expected payments of 32.

Note that the marginal cost to the bidder of winning the auction when the highest value of any other bidder is $v$ can be calculated as the derivative of expected payments with respect to the probability of winning when the highest-value type of bidder you are defeating has a value of $v, d P(v) / d F^{n-1}(v)=v$. This is a necessary condition for a symmetric equilibrium for any type of auction that always awards the object to the highest bidder since a bidder with a value of $v$ must be just indifferent to bidding enough to beat a competitor with the same value. The expected surplus of a bidder is the area $S(v)$, which equals the bidder's value times his probability of winning the auction less expected payments. Inspection of figure Al indicates the following formulae:

$$
\begin{gathered}
S(v)=\int_{\underline{v}}^{v} F^{n-1}(x) d x \\
P(v)=v F^{n-1}(v)-S(v)=\int_{\underline{v}}^{v} x d F^{n-1}(x), \\
B(v)=\frac{P(v)}{F^{n-1}(v)}=v-\frac{\int_{v}^{v} F^{n-1}(x) d x}{F^{n-1}(v)} .
\end{gathered}
$$

We now consider first-price auctions. Assume that each bidder with value $v$ bids an amount $B(v)$, which, in terms of figure A2, equates area $C$ and area $D$. In the numerical example, the bidder with a value of 80 bids 40 , paying more in the first-price auction than in the second-price auction whenever the second-highest bidder's value is below 40 (the difference represented by area $C$ ) and less when the second-highest bidder's value is above 40 (represented by $D$ ).

If everyone's bidding $B(v)$ is an equilibrium, "revenue equivalence" will hold: the bidder with the highest value will win both auctions and make the same expected payments in either because $B(v)$ is the expected bid in the second-price auction. However, to prove that this is an equilibrium, we must show that if all $(n-1)$ other bidders follow this strategy, then it will pay the $n$th bidder to follow the same strategy.

Note first that under the specified strategies, the bidder with value $v$ wins with probability $F^{n-1}(v)$ and gets expected surplus $[v-B(v)] F^{n-1}(v)=$ $v F^{n-1}(v)-P(v)$. Now consider what happens if he decides to deviate by bidding less than the specified amount. Let the deviation be to bid only $B\left(v^{\prime}\right)$, $v^{\prime}<v$, as in figure A3.

By making the lower bid, which will succeed only with probability $F^{n-1}\left(v^{\prime}\right)$, the bidder reduces his expected payment to $B\left(v^{\prime}\right) F^{n-1}\left(v^{\prime}\right)=P\left(v^{\prime}\right)$, a reduction of $H+I+J$ or, equivalently, $G+H$. However, his expected gross benefits fall by $G+H+F$, so the buyer's net surplus is now only $v F^{n-1}\left(v^{\prime}\right)-P\left(v^{\prime}\right)$, a net reduction of area $F$. So the deviation is not worthwhile. In the example, if 


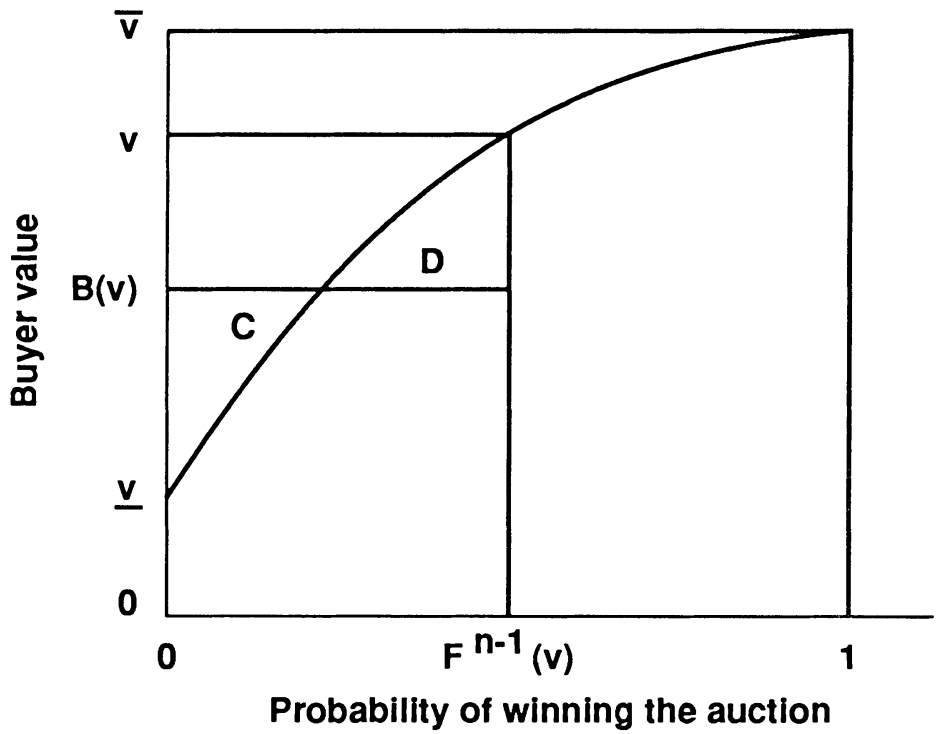

FIG. A2

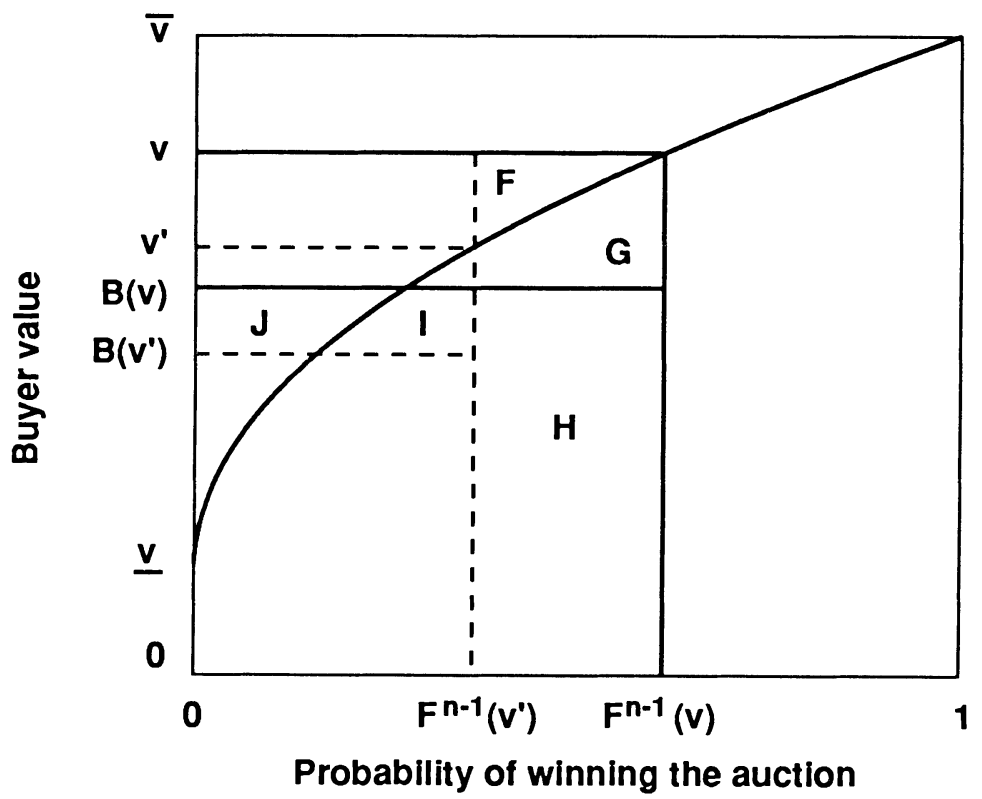

FIG. A3 
a bidder with a value of 80 acted like a bidder with value 70 and so bid 35 , his expected payments would drop from $.8 \times 40=32$ to $.7 \times 35=24.5$. However, net surplus would fall from $.8(80)-32=32$ to $.7(30)-24.5=$ 31.5. Analogously, expected surplus is reduced by bidding more than $B(v)$. Thus the specified strategies constitute a (Bayesian) Nash equilibrium and so revenue equivalence obtains.

The analysis above can be easily modified to allow for the seller's imposing a common reservation price or minimum bid. Instead of graphing $v$ against $F^{n-1}(v)$, graph $M(v, r)=\max (v, r)$ against $F^{n-1}(v)$. The term $M(v, r)$ can be thought of as the marginal cost of winning the auction against a bidder with value $v$, or $M(v, r)=d P(v, r) / d F^{n-1}(v)$. In a second-price auction, a bidder with a value of $v \geq r$ will bid $v$ and make expected payments of $P(v, r)$. In a first-price auction, such a bidder will offer $B(v, r)=P(v, r) / F^{n-1}(v)$. In the example, a bidder with a value of 80 facing a reservation price of 50 will bid 80 in a second-price auction and make expected payments of $50 \times .5+65 \times$ $.3+0 \times .2=44.5,{ }^{13}$ or $44.5 / .8=55.625=B(80,50)$ contingent on winning the auction. In the first-price auction the equilibrium bid is 55.625 .

It is also easy to derive a revenue equivalence result graphically for multiple-goods auctions, where the seller is offering $k$ identical goods and each buyer wants only one unit. Simply graph $v$ (or $M(v, r)$ to allow for reservation prices) against $F_{k}^{n-1}(v)$, where $F_{k}^{n-1}(v)$ is the probability that the $k$ th-highest value among the $n-1$ other bidders is less than or equal to $v$ (and so represents the probability that a buyer with a value of $v$ will make a successful bid in a symmetric equilibrium). If we apply the same analysis as before, it is easy to show revenue equivalence between an auction that allocates items to the top $k$ bidders who all pay the $(k+1)$ st-highest bid and an auction that allocates items to the top $k$ bidders who each pay their own bid.

Finally, the same graphical technique can be employed to show revenue equivalence for other forms of auctions, such as the all-pay auction in which all bidders pay their bid regardless of whether they win. The equilibrium allpay bid for a bidder with a value greater than $r$ is just $P(v, r)$-the expected payment the bidder would make in a first- or second-price auction.

\section{References}

Baron, David P., and Myerson, Roger B. "Regulating a Monopolist with Unknown Costs." Econometrica 50 (July 1982): 911-30.

Chatterjee, Kalyan, and Samuelson, William. "Bargaining under Incomplete Information.” Operations Res. 31 (September-October 1983): 835-61.

Cramton, Peter; Gibbons, Robert; and Klemperer, Paul. "Dissolving a Partnership Efficiently.” Econometrica 55 (May 1987): 615-32.

Harris, Milton, and Raviv, Artur. "Allocation Mechanisms and the Design of Auctions.” Econometrica 49 (November 1981): 1477-99. (a)

- "A Theory of Monopoly Pricing Schemes with Demand Uncertainty." A.E.R. 71 (June 1981): 347-65. (b)

Hotelling, Harold. "The Economics of Exhaustible Resources." J.P.E. 39 (April 1931): 137-75.

${ }^{13}$ Half the time the other bidder will have a value of less than 50 , so the bidder will pay 50; 30 percent of the time the other bidder's value will be between 50 and 80 , and the bidder will pay an average of 65 ; and 20 percent of the time the bidder will lose the auction and pay nothing. 
McAfee, R. Preston, and McMillan, John. "Auctions and Bidding." J. Econ. Literature 25 (June 1987): 699-738.

Maskin, Eric S., and Riley, John G. "Monopoly with Incomplete Information." Rand J. Econ. 15 (Summer 1984): 171-96. (a)

- "Optimal Auctions with Risk Averse Buyers." Econometrica 52 (November 1984): 1473-1518. (b)

Matthews, Steven A. "Selling to Risk Averse Buyers with Unobservable Tastes." J. Econ. Theory 30 (August 1983): 370-400.

Milgrom, Paul R. "The Economics of Competitive Bidding: A Selective Survey." In Social Goals and Social Organization: Essays in Memory of Elisha Pazner, edited by Leonid Hurwicz, David Schmeidler, and Hugo Sonnenschein. Cambridge: Cambridge Univ. Press, 1985.

- "Auction Theory." In Advances in Economic Theory: Fifth World Congress, edited by Truman F. Bewley. Cambridge: Cambridge Univ. Press, 1987. 1989).

Milgrom, Paul R., and Weber, Robert J. "A Theory of Auctions and Competitive Bidding." Econometrica 50 (September 1982): 1089-1122.

Mussa, Michael, and Rosen, Sherwin. "Monopoly and Product Quality." J. Econ. Theory 18 (August 1978): 301-17.

Myerson, Roger B. “Optimal Auction Design.” Math. Operations Res. 6 (February 1981): 58-73.

Myerson, Roger B., and Satterthwaite, Mark A. "Efficient Mechanisms for Bilateral Trading." J. Econ. Theory 29 (April 1983): 265-81.

Pratt, John, and Zeckhauser, Richard. "Smoothing the Bumps in Profit Maximization: Pro Rata Tenders, Monopolist's Roulette, and Other Rationed Transactions." Manuscript. Cambridge, Mass.: Harvard Univ., Kennedy School Government, 1986.

Riley, John G., and Samuelson, William F. "Optimal Auctions." A.E.R. 71 (June 1981): 381-92.

Vickrey, William. "Counterspeculation, Auctions, and Competitive Sealed Tenders.” J. Finance 16 (March 1961): 8-37.

Wilson, Robert B. "Incentive Efficiency of Double Auctions." Econometrica 53 (September 1985): 1101-15. 
http://www.jstor.org

\title{
LINKED CITATIONS
}

- Page 1 of 3 -

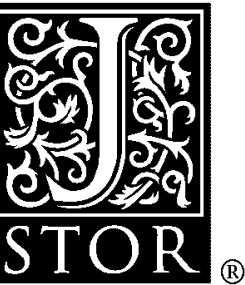

You have printed the following article:

\section{The Simple Economics of Optimal Auctions}

Jeremy Bulow; John Roberts

The Journal of Political Economy, Vol. 97, No. 5. (Oct., 1989), pp. 1060-1090.

Stable URL:

http://links.jstor.org/sici?sici=0022-3808\%28198910\%2997\%3A5\%3C1060\%3ATSEOOA\%3E2.0.CO\%3B2-8

This article references the following linked citations. If you are trying to access articles from an off-campus location, you may be required to first logon via your library web site to access JSTOR. Please visit your library's website or contact a librarian to learn about options for remote access to JSTOR.

\section{[Footnotes]}

\author{
${ }^{1}$ Incentive Efficiency of Double Auctions \\ Robert Wilson \\ Econometrica, Vol. 53, No. 5. (Sep., 1985), pp. 1101-1115. \\ Stable URL: \\ http://links.jstor.org/sici?sici=0012-9682\%28198509\%2953\%3A5\%3C1101\%3AIEODA\%3E2.0.CO\%3B2-3

\section{${ }^{1}$ Regulating a Monopolist with Unknown Costs} \\ David P. Baron; Roger B. Myerson \\ Econometrica, Vol. 50, No. 4. (Jul., 1982), pp. 911-930. \\ Stable URL: \\ http://links.jstor.org/sici?sici=0012-9682\%28198207\%2950\%3A4\%3C911\%3ARAMWUC\%3E2.0.CO\%3B2-Y

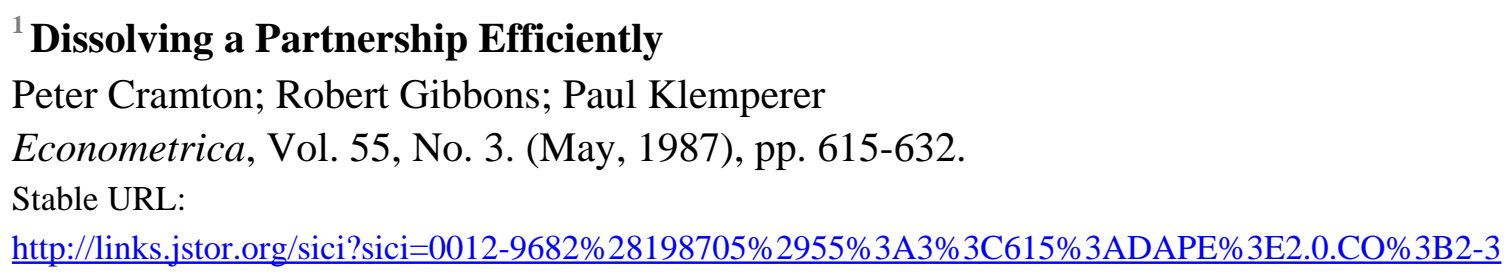

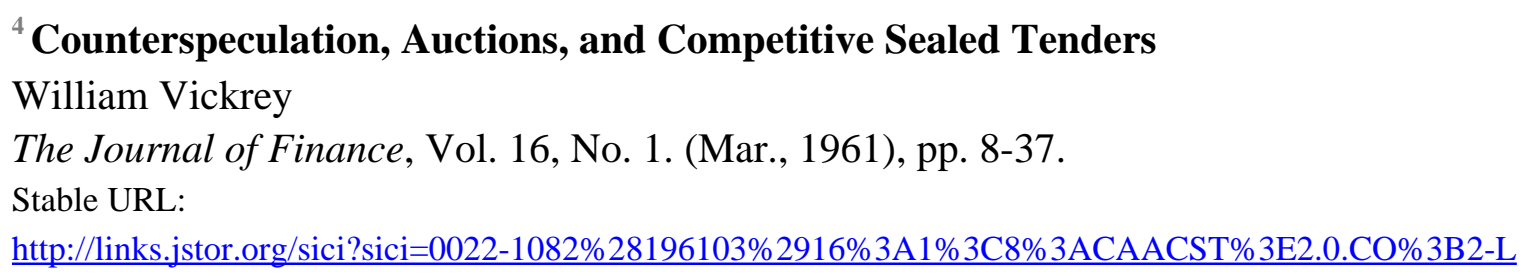

NOTE: The reference numbering from the original has been maintained in this citation list. 
http://www.jstor.org

\section{LINKED CITATIONS}

- Page 2 of 3 -

\footnotetext{
${ }^{4}$ A Theory of Auctions and Competitive Bidding

Paul R. Milgrom; Robert J. Weber

Econometrica, Vol. 50, No. 5. (Sep., 1982), pp. 1089-1122.

Stable URL:

http://links.jstor.org/sici?sici=0012-9682\%28198209\%2950\%3A5\%3C1089\%3AATOAAC\%3E2.0.CO\%3B2-E
}

\section{References}

\section{Regulating a Monopolist with Unknown Costs}

David P. Baron; Roger B. Myerson

Econometrica, Vol. 50, No. 4. (Jul., 1982), pp. 911-930.

Stable URL:

http://links.jstor.org/sici?sici=0012-9682\%28198207\%2950\%3A4\%3C911\%3ARAMWUC\%3E2.0.CO\%3B2-Y

\section{Dissolving a Partnership Efficiently}

Peter Cramton; Robert Gibbons; Paul Klemperer

Econometrica, Vol. 55, No. 3. (May, 1987), pp. 615-632.

Stable URL:

http://links.jstor.org/sici?sici=0012-9682\%28198705\%2955\%3A3\%3C615\%3ADAPE\%3E2.0.CO\%3B2-3

\section{Allocation Mechanisms and the Design of Auctions}

Milton Harris; Artur Raviv

Econometrica, Vol. 49, No. 6. (Nov., 1981), pp. 1477-1499.

Stable URL:

http://links.jstor.org/sici?sici=0012-9682\%28198111\%2949\%3A6\%3C1477\%3AAMATDO\%3E2.0.CO\%3B2-5

\section{Optimal Auctions with Risk Averse Buyers}

Eric Maskin; John Riley

Econometrica, Vol. 52, No. 6. (Nov., 1984), pp. 1473-1518.

Stable URL:

http://links.jstor.org/sici?sici=0012-9682\%28198411\%2952\%3A6\%3C1473\%3AOAWRAB\%3E2.0.CO\%3B2-0

NOTE: The reference numbering from the original has been maintained in this citation list. 
http://www.jstor.org

\title{
LINKED CITATIONS \\ - Page 3 of 3 -
}

\author{
A Theory of Auctions and Competitive Bidding \\ Paul R. Milgrom; Robert J. Weber \\ Econometrica, Vol. 50, No. 5. (Sep., 1982), pp. 1089-1122. \\ Stable URL: \\ http://links.jstor.org/sici?sici=0012-9682\%28198209\%2950\%3A5\%3C1089\%3AATOAAC\%3E2.0.CO\%3B2-E
}

\section{Counterspeculation, Auctions, and Competitive Sealed Tenders}

William Vickrey

The Journal of Finance, Vol. 16, No. 1. (Mar., 1961), pp. 8-37.

Stable URL:

http://links.jstor.org/sici?sici=0022-1082\%28196103\%2916\%3A1\%3C8\%3ACAACST\%3E2.0.CO\%3B2-L

\section{Incentive Efficiency of Double Auctions}

Robert Wilson

Econometrica, Vol. 53, No. 5. (Sep., 1985), pp. 1101-1115.

Stable URL:

http://links.jstor.org/sici?sici=0012-9682\%28198509\%2953\%3A5\%3C1101\%3AIEODA\%3E2.0.CO\%3B2-3 